\title{
IDENTIFICATION AND STRUCTURAL CHARACTERIZATION OF $\mathrm{Ca}\left(\mathrm{Pt}_{\mathrm{x}} \mathrm{Cu}_{(1-\mathrm{x})}\right)_{3} \mathrm{O}_{4}$
}

\author{
N.L. Wu ${ }^{1}$, D.S. Wu ${ }^{1}$, I.A. Rusakova ${ }^{2}$, D.K. Ross ${ }^{2}$, and P.W. Stephens ${ }^{3}$ \\ ${ }^{1}$ Department of Chemical Engineering, National Taiwan University, \\ Taipei 106, Taiwan, ROC \\ ${ }^{2}$ Texas Center for Superconductivity at the University of Houston, \\ Houston, TX 77204-5932, USA \\ ${ }^{3}$ Department of Physics and Astronomy, SUNY Stony Brook, \\ Stony Brook, NY 11794-3800, USA
}

(Refereed)

(Received February 2, 1999; Accepted March 11, 1999)

\begin{abstract}
We describe a new compound, $\mathrm{Ca}\left(\mathrm{Pt}_{\mathrm{x}} \mathrm{Cu}_{(1-\mathrm{x})}\right)_{3} \mathrm{O}_{4}(0.2<\mathrm{x}<0.3)$, which is only the second- known quaternary compound of an alkaline earth metal with platinum, copper, and oxygen. The composition and structure were determined with an electron probe using wave-dispersive spectrometry (WDS), electron diffraction, and powder X-ray diffraction. The present material crystallizes in the Pt bronze structure, a cubic cell with $a=5.6270(2) \AA$, and space group $P m \overline{3} n$ (no. 223). The $\mathrm{Cu}$ and $\mathrm{Pt}$ atoms are randomly distributed onto the same position, comprising nonintersecting chains in each of the three coordinate directions. The material is an n-type semiconductor. $\odot 2000$ Elsevier Science Ltd
\end{abstract}

KEYWORDS: A. oxides, A. semiconductors, C. X-ray diffraction, D. crystal structure

\section{INTRODUCTION}

Platinum is used extensively as a crucible material in high-temperature chemical processes. One strong motivation for understanding its reactivity with alkaline earth (AE) metals in the presence of $\mathrm{Cu}$ arises from its application in the processing of high- $\mathrm{T}_{\mathrm{c}}$ superconducting

*To whom correspondence should be addressed. 
cuprates, all of which contain at least one AE metal. The present material was first detected in the residue left on a Pt crucible where a mixture of $\mathrm{CaCuO}_{2}$ and $\mathrm{CuO}$ was melted at $1050^{\circ} \mathrm{C}$. The chemical composition was determined by wave- dispersive spectrometry (WDS) using an electron microprobe, and the approximate composition was used to prepare samples that were essentially phase-pure.

To our knowledge, several ternary AE-Pt-O and $\mathrm{Pt}-\mathrm{Cu}-\mathrm{O}$ compounds have been identified, such as $\mathrm{CaPt}_{2} \mathrm{O}_{4}$ [1], $\mathrm{Ca}_{2} \mathrm{Pt}_{3} \mathrm{O}_{8}$ [2], $\mathrm{M}_{4} \mathrm{PtO}_{6}$ (where $\mathrm{M}=\mathrm{Ba}$ or $\mathrm{Ca}$ ) [3-5], $\mathrm{Cu}_{0.8} \mathrm{Pt}_{0.2} \mathrm{O}$, and $\mathrm{Cu}_{3} \mathrm{PtO}_{6}[6]$, but only one quaternary $\mathrm{AE}-\mathrm{Pt}-\mathrm{Cu}-\mathrm{O}$ compound, namely, $\mathrm{Ba}_{4} \mathrm{Pt}_{1-\mathrm{x}} \mathrm{Cu}_{2-\mathrm{x}} \mathrm{O}_{9-\mathrm{z}}[7]$.

\section{EXPERIMENTAL}

Bulk samples of $\mathrm{Ca}\left(\mathrm{Pt}_{\mathrm{x}} \mathrm{Cu}_{(1-\mathrm{x})}\right)_{3} \mathrm{O}_{4}$ were prepared by calcining mixtures containing $\mathrm{CaO}, \mathrm{CuO}$, and $\mathrm{Pt}$ metal powders at $1050^{\circ} \mathrm{C}$ in flowing oxygen. The samples were furnace-cooled in oxygen and ground after every $10 \mathrm{~h}$ of heat treatment, and parts of the samples were analyzed by laboratory X-ray diffraction (XRD). While the diffraction patterns were found to become unchanged after $10 \mathrm{~h}$ of heat treatment, an additional $20 \mathrm{~h}$ was imposed to ensure complete reaction.

Chemical analysis was carried out by WDS [8] with a JEOL 8600 electron probe, which had been calibrated using compounds with known compositions $\left(\mathrm{Cu}\right.$ and $\mathrm{O}$ calibrated on $\mathrm{Cu}_{2} \mathrm{O}$, $\mathrm{Ca}$ on $\mathrm{CaMgSi}_{2} \mathrm{O}_{6}$, Pt on Pt metal) and had an accuracy of $\pm 3 \%$. Electron diffraction was conducted with a JEOL 2000FX transmission electron microscope (TEM), which operated at 200 $\mathrm{kV}$ and was equipped with an energy-dispersive X-ray (EDX) analyzer. The samples were prepared by crushing, and small particles were dispersed on a holed carbon film (Ni grid).

Laboratory powder XRD was carried out under step-scan mode $\left(3 \mathrm{sec} / 0.02^{\circ}\right)$ with a Mac Science/MXP diffractometer using $\mathrm{Cu} \mathrm{K} \alpha$ radiation. Initial synchrotron XRD data were collected at an X-ray wavelength of $0.49935 \AA$ in a capillary of $0.65 \mathrm{~mm}$ diameter at beamline X3B1 of the National Synchrotron Light Source at Brookhaven National Laboratory. The diffractometer is based on a $\mathrm{Si}(111)$ monochromator and $\mathrm{Ge}(111)$ analyzer, with a commercial $\mathrm{NaI}(\mathrm{Tl})$ scintillation detector. The capillary geometry was chosen to eliminate the possibility of preferred orientation before the cubic lattice was known. Once the structure was determined from these data, we collected additional spectra of several samples for refinement, using samples side-drifted into a flat-plate sample holder, at an X-ray wavelength of $1.15 \AA$.

Electrical characterization was carried out on bar-shaped bulk samples. The resistivity was determined by the standard four-point method, while the carrier type was determined by Hall effect measurement under a field of 0.6 Tesla at room temperature.

\section{RESULTS AND DISCUSSION}

Backscattering microscopy and WDS analyses showed that the original residue contained predominantly one quaternary oxide, whose cation compositions showed a fairly constant $(\mathrm{Pt}+\mathrm{Cu}) / \mathrm{Ca}$ ratio of $\sim 3.0( \pm 3 \%)$ but some spreading in the $\mathrm{Pt} / \mathrm{Cu}$ ratio near $0.4( \pm 15 \%)$. Bulk samples with the cation composition of $\mathrm{Ca}: \mathrm{Pt}: \mathrm{Cu}=1: 3 \mathrm{x}: 3(1-\mathrm{x})$, where $\mathrm{x}$ varies from 0.1 to 0.4 with a minimum increment of 0.03 , were thus prepared and subjected to laboratory $\mathrm{XRD}$ analysis (Fig. 1). Samples with $\mathrm{x}$ in the range of 0.2 and 0.3 gave essentially the same set of Bragg reflections (Table 1), which also appeared as the major phase in the pattern of the original residue. 


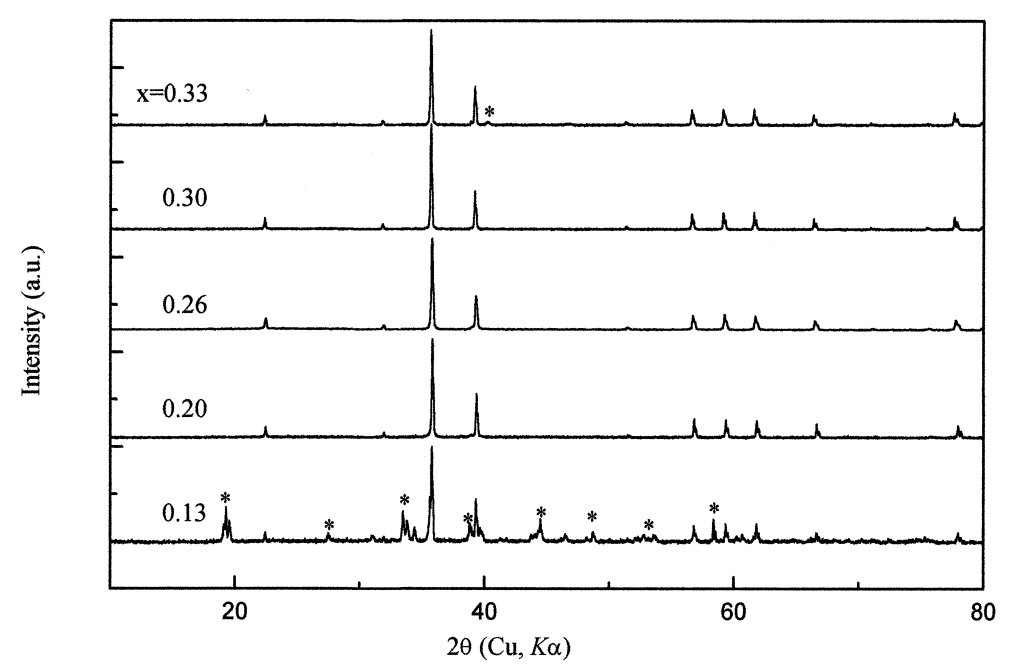

FIG. 1

The $\mathrm{Cu} \mathrm{K} \alpha \mathrm{X}$-ray diffraction patterns for calcined samples of nominal compositions $\mathrm{Ca}\left(\mathrm{Pt}_{\mathrm{x}} \mathrm{Cu}_{(1-\mathrm{x})}\right)_{3} \mathrm{O}_{4}$. Peaks marked with an asterisk (*) are due to impurity phases.

The synchrotron data set for the $\mathrm{x}=0.33$ sample was indexed by noting that the strongest lines were regularly spaced in $\sin ^{2} \theta$, suggesting a cubic lattice. The reflection conditions(00l) $l$ even; $(h h l) l$ even; $(0 k l)$ and $(h k l)$ never extinct except for (014)-indicate either the $P \overline{4} 3 n$ or $P m \overline{3} n$ space group. This symmetry was also observed in the single-crystal electron diffraction patterns. The size of the cell implied that the atoms must be in Wyckoff positions of high symmetry, and trial and error established that the occupations must be a mixture of $\mathrm{Pt}$ and $\mathrm{Cu}$ in $6 c(1 / 4,0,1 / 2), \mathrm{Ca}$ in $2 a(0,0,0)$, and $\mathrm{O}$ in $8 e(1 / 4,1 / 4,1 / 4)$ This assignment exactly matches the $\mathrm{Ca} /(\mathrm{Cu}, \mathrm{Pt})$ ratio determined from WDS. It is also in agreement with density measurement, which, carried out based on the principle of Archimedes, showed a density of $8.2 \pm 0.5$ and hence suggested $Z=2$. No extra diffraction lines or spots due to superstructure were detected in any X-ray or EDX measurements, indicating random mixing between $\mathrm{Pt}$ and $\mathrm{Cu}$. The absence of the (014) peak is consistent with the restriction of atoms to Wyckoff positions $a, c$, and $e$.

Structure refinement was carried out by the Rietveld method, based on the synchrotron XRD pattern of an $\mathrm{x}=0.33$ sample. The result, for space group $P m \overline{3} n$, lattice parameter $a=$ 5.6270(2) $\AA$, is shown in Figure 2. In this spectrum, we can observe weak peaks from two different phases described as $\mathrm{Ca}_{4} \mathrm{PtO}_{6}[4,5]$ and broad, asymmetric lines from an fcc phase with lattice parameter $3.87 \AA$, assumed to be an alloy of $\mathrm{Cu}$ and Pt. Excluding the regions of impurity peaks, the Rietveld fit was $\chi^{2}=7.46$; this rather bad fit can be explained by the difficulties of ascertaining lineshape for inadequately sampled particle statistics with very sharp peaks. We were unable to determine reliable thermal parameters, probably also due to inadequate sampling. The Bragg R-factor of 0.030 (defined as

$$
\sum_{k}\left|I_{k}-I c_{k}\right| \mid \sum_{k} I_{\mathrm{k}}
$$


TABLE 1

The $\mathrm{Cu} \mathrm{K} \alpha \mathrm{X}$-ray Diffraction Data for Nominal Composition $\mathrm{CaPt}_{0.8} \mathrm{Cu}_{2.2} \mathrm{O}_{4}$

\begin{tabular}{rrr}
\hline$h k l$ & $\mathrm{~d}(\AA)$ & $\mathrm{I} / \mathrm{I}_{0}$ \\
\hline 110 & 3.983 & 11 \\
200 & 2.816 & 4 \\
210 & 2.519 & 100 \\
211 & 2.300 & 39 \\
310 & 1.781 & 2 \\
222 & 1.626 & 14 \\
320 & 1.562 & 15 \\
321 & 1.506 & 12 \\
400 & 1.408 & 9 \\
411 & 1.327 & 1 \\
330 & & \\
420 & 1.260 & 1 \\
421 & 1.229 & 9 \\
332 & 1.201 & 2 \\
510 & 1.105 & $<1$ \\
431 & & \\
432 & 1.046 & \\
520 & & 2 \\
521 & 1.029 & 3 \\
440 & 0.996 & $<1$ \\
442 & 0.939 & \\
600 & & \\
610 & 0.926 & \\
532 & 0.914 & \\
611 & & \\
\hline & &
\end{tabular}

for experimental observations $I_{k}$ and calculated intensities $I c_{k}$ ) is more appropriate for the present case of fully resolved peaks. The fractional Pt occupancy $x$ refines to $0.22 \pm 0.05$. The spectrum is also consistent with space group $P \overline{4} 3 n$, representing a particular (unlikely) buckling of the four oxygens surrounding each $(\mathrm{Pt}, \mathrm{Cu})$, with a maximum allowed oxygen displacement of $0.3 \AA$.

In order to explore the limit of $\mathrm{Pt}: \mathrm{Cu}$ composition, we collected a synchrotron $\mathrm{X}$-ray powder pattern from an $\mathrm{x}=0.13$ sample. That sample had larger amounts of both $\mathrm{Ca}_{4} \mathrm{PtO}_{6}$ phases and a trace of $\mathrm{CuO}$ along with the $\mathrm{Ca}(\mathrm{Pt}, \mathrm{Cu})_{3} \mathrm{O}_{4}$ phase described here. The other phases were so strong that it was not possible to obtain a Rietveld refinement, but three peaks were observed without significant contamination, and their ratio implied a Pt occupancy $x$ in the range of $0.22 \pm 0.08$. The lattice parameter was $5.622(1) \AA$.

Figure 3 shows the overall view of the crystal structure of the present material. Infinite chains of $(\mathrm{Cu}, \mathrm{Pt})$ extend, parallel to the edges of the unit cube. They are tied together by oxygen ions to form interlocking cages, at the center of which are $\mathrm{Ca}$ ions. Each $(\mathrm{Cu}, \mathrm{Pt})$ ion is surrounded by four oxygen ions in square planar coordination, while each $\mathrm{Ca}$ ion has eight oxygen ions as its closest neighbors. No unusual bond distances or coordinates can be seen 


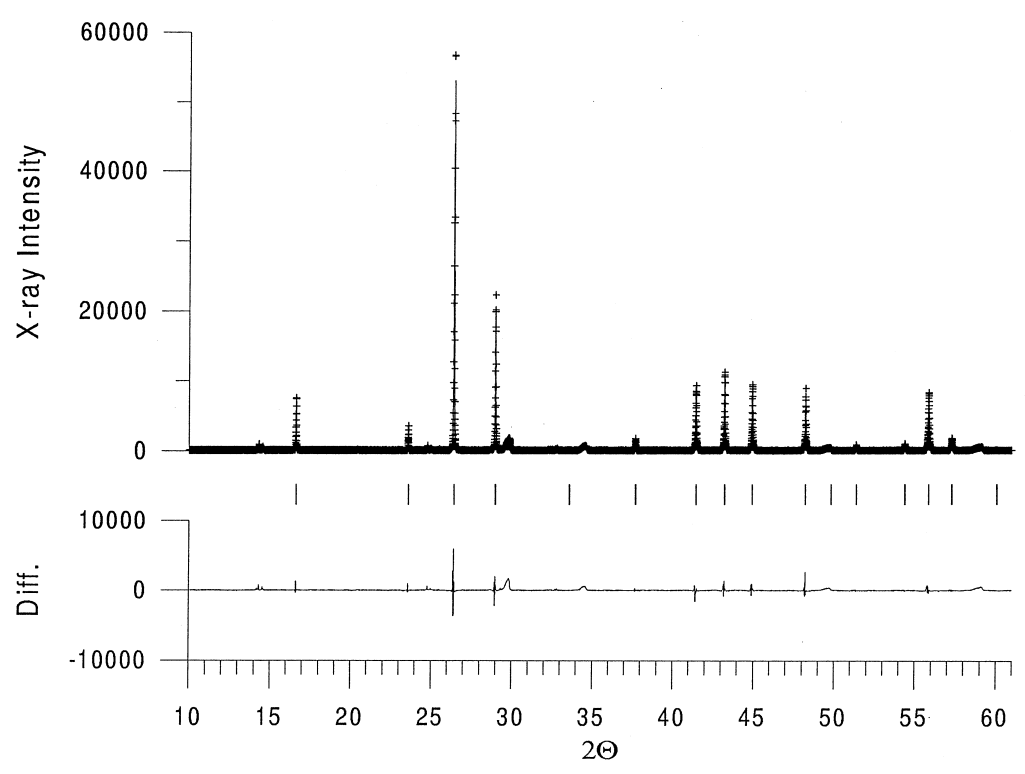

FIG. 2

Rietveld refinement of a sample of nominal composition $\mathrm{CaPtCu}_{2} \mathrm{O}_{4}$.

(Table 2). The $\mathrm{Ca}-\mathrm{O}$ distance is $2.437 \AA$, while the $(\mathrm{Cu} / \mathrm{Pt})-\mathrm{O}$ distance is $1.989 \AA$. The $s p^{2}$ hybridization of the oxygen atoms accounts for the planar-triangular bonding to $(\mathrm{Cu}, \mathrm{Pt})$ ions.

This material is isostructural to the well-known platinum bronzes, which have a general formula of $\mathrm{M}_{\mathrm{y}} \mathrm{Pt}_{3} \mathrm{O}_{4}$ [9]. Known $\mathrm{M}$ metals include $\mathrm{Na}, \mathrm{Mg}, \mathrm{Ni}$, and $\mathrm{Cd}$, with y being no greater than 1.0. By taking the normal valence of the $\mathrm{M}$ element, such as +1 for $\mathrm{Na},+2$ for $\mathrm{Mg}$, and $\mathrm{Cd}$, and +2 to about +4 for $\mathrm{Ni}$, and multiplying it by the known y values, one

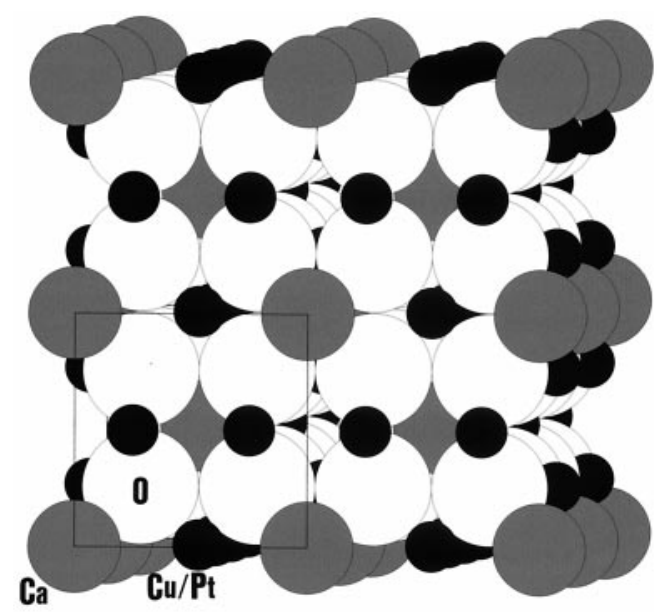

FIG. 3

The proposed structure of $\mathrm{Ca}\left(\mathrm{Pt}_{\mathrm{x}} \mathrm{Cu}_{(1-\mathrm{x})}\right)_{3} \mathrm{O}_{4}$. 
TABLE 2

\begin{tabular}{lr}
\multicolumn{2}{c}{ Interatomic Distances $(\AA)$} \\
\hline$(\mathrm{Cu}, \mathrm{Pt})-\mathrm{O}$ & 1.989 \\
$(\mathrm{Cu}, \mathrm{Pt})-(\mathrm{Cu}, \mathrm{Pt})$ & 2.813 \\
$(\mathrm{Cu}, \mathrm{Pt})-\mathrm{Ca}$ & 3.146 \\
$\mathrm{O}-\mathrm{O}$ & 2.813 \\
$\mathrm{Ca}-\mathrm{O}$ & 2.437 \\
\hline
\end{tabular}

readily finds out that the total valence contributed by the $\mathrm{M}$ ions is no greater than +1 per formula in the known Pt bronzes. Cahen et al. [1] attempted to prepare $\mathrm{Ca}_{\mathrm{x}} \mathrm{Pt}_{3} \mathrm{O}_{4}$ but ended up with $\mathrm{CaPt}_{2} \mathrm{O}_{4}$, which has a structure similar to the bronzes, except that the Pt chain along one of the axes is systematically missing. It appears that there existed a minimum valence, no less than $7 / 3$, for Pt ions to be stable in the square-planar coordination with oxygen. When the minimum valence was not fulfilled, stability was regained by reducing Pt ions in each unit cell, as in the case of $\mathrm{CaPt}_{2} \mathrm{O}_{4}$, or by replacing Pt with another element that could take a lower valence than Pt. The latter has been demonstrated previously for $\mathrm{CdPd}_{3} \mathrm{O}_{4}$ [10] and $\mathrm{CaPd}_{3} \mathrm{O}_{4}$ [11], and now in the present compound. The observed $\mathrm{Pt}: \mathrm{Cu}$ ratio in the present compound coincides well with $\mathrm{Cu}_{0.8} \mathrm{Pt}_{0.2} \mathrm{O}$ [6], where the $\mathrm{Cu} / \mathrm{Pt}$ ion is also in square-planar coordination with oxygen ions.

Resistivity measurements of samples with $\mathrm{x}=0.2$ to $\sim 0.3$ gave data characteristic of a semiconductor, showing an increase in resistivity with decreasing temperature. The roomtemperature resistivities of the polycrystalline samples were found to decrease with increasing Pt content, ranging from $0.8 \Omega$-cm for $\mathrm{x}=0.3$ to $9.9 \Omega-\mathrm{cm}$ for $\mathrm{x}=0.2$. Hall effect measurements indicated electrons (i.e., n-type) to be the major carrier. This is in great contrast to metallic $\mathrm{Ni}_{\mathrm{x}} \mathrm{Pt}_{3} \mathrm{O}_{4}$ and p-type semiconducting $\mathrm{CaPd}_{3} \mathrm{O}_{4}$.

\section{ACKNOWLEDGMENTS}

This work was supported by the National Science Council of the Republic of China under contract number NSC86-2113-M-002-006. Research was carried out in part at the National Synchrotron Light Source at Brookhaven National Laboratory, which is supported by the U.S. Department of Energy, Division of Materials Sciences and Division of Chemical Sciences. The SUNY X3 beamline at NSLS was supported by the Division of Basic Energy Sciences of the U.S. Department of Energy under Grant No. DE-FG02-86ER45231. The TEM and electron probe were supported by the State of Texas through funding for the Texas Center for Superconductivity at the University of Houston.

\section{REFERENCES}

1. D. Cahen, J.A. Ibers, and M.H. Mueller, Inorg. Chem. 13, 110 (1974).

2. X. Turrillas, C. Laviron, H. Vincent, J. Pannetier, and J.C. Joubert, J. Solid State Chem. 67, 297 (1987).

3. S.J. Schneider and C.L. McDaniel, J. Am. Ceram. Soc. 52, 518 (1969).

4. R. Czaya, Z. Anorg. Allg. Chem. 375, 61 (1970); JCPDS file no. 23-860. 
5. JCPDS file no. 23-862.

6. O. Muller and R. Roy, J. Less-Common Met. 19, 209 (1969).

7. JCPDS file 40-302.

8. E.P. Bertin, Introduction to X-ray Spectrometric Analysis, Plenum Press, New York (1978), Chaps. 1-4, 6, 7, 9.

9. J. Waser and E.D. McClanahan, Jr., J. Chem. Phys. 19, 413 (1951).

10. O. Muller and R. Roy, Advan. Chem. Ser. 98, 28 (1971).

11. R.C. Wnuk, T.R. Touw, and B. Post, IBM J. Res. Devel. 8, 185 (1964). 